\title{
The Semiotics of Education: A New Vision in an Old Landscape
}

Eetu Pikkarainen, University of Oulu, 2009-06-23

[Preprint version of: http://onlinelibrary.wiley.com/doi/10.1111/j.1469-5812.2009.00632.x/abstract]

\begin{abstract}
In this article, my attempt is to describe how certain theoretical constructions of semiotics could be applied in educational theoretical work. First I will introduce meaning as a basic concept of semiotics, thus also touching on concepts such as action, competence and causality. I will then be able to define learning as a change of competences, and will also shortly refer to the pedagogical concept of learning i.e. Bildung, which can be roughly defined as valuable human learning ${ }^{1}$. I will then take up the problem of education as pedagogical direction and communication. Finally, I will conclude with some considerations on the famous Greimassian semiotic square.
\end{abstract}

\section{Introduction}

One could suggest that semiotics, the study and theory of signs, meanings and communication, could be a valuable tool within education and educational sciences, offering different perspectives. However, there have been surprisingly few studies in which semiotic theory and methods have been applied to education. These studies have been quite heterogeneous, which has been the case of semiotic writing in many other fields as well. Furthermore, these projects of inquiry have mostly been quite pragmatic and empirical in nature, or have involved normative reflection in relation to specific questions within education, such as certain school subjects ${ }^{2}$. Andrew Stables' recent work on semiotic engagement as a new theory of education stands out as a most delightful exception (Stables, 2005, Stables \& Gough, 2006).

I have tried to develop a more general theoretical use of semiotics in education in my Doctoral thesis (Pikkarainen, 2004) and in some conference presentations, but until now I have written very little about this project in English. My views have a lot in common with those of Andrew Stables but there are also some significant differences. One difference could be explained by our differing backgrounds: Stables' context is Anglo-American philosophy and policy of education, and he does not clearly commit himself to any specific semiotic school or tradition. Rather, he quite freely uses certain Saussurean and post-structuralistic concepts. My background, on the other hand, is in the Scandinavian and continental European educational - or rather, pedagogical - tradition; and my 
main semiotic inspiration is based on Greimas, which I have interpreted through bio-semiotics and action theory. Secondly, Stables also seems to be developing a quite practical and very radical critique of contemporary educational theory as well as praxis. My enterprise is perhaps more modest: In particular, I have suggested that semiotics would be helpful when trying to translate some old and vague theoretical views of education to modern, more Anglo-American, scientific language. I will not be analysing Stables' theory more profoundly in this article.

\section{Meaning and action as the basis of semiotics}

Semiotics is often defined as study of signs. If we are asked what signs are, we may either give some concrete examples of signs, or, if we try to provide a more theoretical and comprehensive answer, we might suggest that signs are parts of a sign system. It is justifiable to say that single signs cannot exist in isolation; signs are always connected to each other in one way or another and together they form some kind of a system or structure. If, then, we are asked what a sign system is, we can, again, either give an example or describe it as a system of signs. This description is, of course, a caricature, and much more can be said about signs. Nevertheless, this situation fits in well with the idea of the inter-definition of scientific terms. However, we will here break the interdefinition circle and start from a bio-semiotical notion, which is: there are signs only in the environment of living beings. In other words, we could say that signs are based on life, they are that of which the environment ('Umwelt') of living beings consists (von Uexküll, 1982).

Instead of the vague biological concept of life, I will take a more familiar one and propose that living beings are constantly doing something and that is why they have signs in their environment. Here, the 'things' that living beings are doing can be called actions. (Life could then be considered the entity of living beings' all actions.) Although action is quite a familiar concept, it can be analyzed and clarified according to the lines of standard theories of action (cf. e.g. Davis, 1979, Moya, 1990, for semiotic applications see: Stockinger, 1989, Greimas \& Courtés, 1982). Action can be described as consisting of deeds, where a subject of action causes an event in an object within the surrounding environment. This one-way happening can be broadened to a two-way, or rather, a circular structure where the object in a subject's environment causes a feed-back effect on the subject. Thus action consists of a subject's deeds and the feed-back of the environment. These are circularly interconnected so that deeds affect the environment, thus causing changes in feed-back effects, and respectively feed-back effects cause changes in a subject's deeds. 
What is extremely important here is the relative independence of the poles within the circle. Only a few changes in the environment are usually caused by a subject's deeds - rather, the environment is in a continuous process of change. Nevertheless, and more importantly, we refer to the events caused by the subject as deeds only if they are caused more or less independently by the subject itself. We may often think that the processes of the environment consist of causal chains in which each event is caused and can be explained causally by some other - usually earlier - event. If we dislike the idea of determinism, we can add the effect of chance to the figure. It still remains that we think differently about the subject and its deeds. A deed cannot and must not be explained exhaustively by some other events of the environment (plus chance), but they must be at least partly caused by the subject itself. The subject must want, choose, or decide for itself to do the deed. In philosophy, this internal causation is often called intentionality: a deed is done intentionally. In law and education we usually use the term motivation. Only if subjects have done the deeds themselves, can they be responsible for them.

This is, therefore, the problem: How does the interaction of subjects and their environment work if subjects act adequately in the environment, but the environment does not cause its deeds? Here, I will provide a bio-semiotical example: The wind causes a tree to fall. This is what we usually call causal causation. A rabbit is sitting on a spot where the tree is about to fall on. If the rabbit stays where it is, it will get squashed and die - this would also be a causal event. However, if the rabbit sees, or rather, hears the tree falling, it will jump away. We might say that jumping away is the rabbit's own deed that was caused intentionally by itself, but we might also want to suggest that the falling of the tree caused the rabbit to jump. It jumped because of the falling tree. We can understand and conclude that the threatening situation of being squashed under the falling tree is the reason for its jumping away. But this frightening, unfortunate event cannot of course cause the jumping causally, because it never actually took place at all.

We could solve the previous problem by saying that this familiar but still almost mysterious, or at least very complicated way in which such effects of the environment cause the deeds or affect the action of a subject is a case of meaning effects. The parts, objects or events of the environment which cause meaning effects can be referred to as signs (or rather, sign structures $^{3}$ ), and the contents or descriptions of such effects as meanings. Signs and their meanings do not vary randomly, but rather, they operate very consistently and logically - the preservation of living beings mainly depends on the consistency and adequacy of meaning effects. Therefore, it must be possible to study them scientifically - although the scientific nature may somewhat differ from the physical 
or natural sciences which focus on causal effects. Semiotics is a science which examines how sign structures cause meaning effects.

Based on the definition that meaning is a way how an object (thing, event etc.) in the environment affects the subject's action, we can differentiate between three separate and quite important levels of meaning. The first level is the objective level, which is based on causal effects. For example, the falling of the tree on the rabbit would most certainly affect the rabbit's action. However, in semiotics, the main interest is not at this level. Nevertheless, it can be concluded that the rabbit's action of jumping was based on the possibility and anticipation of this objective "meaning". The second level of meaning is subjective meaning, which is the essential core of meaning effects. It is something which happens 'inside' the subject and thus it is hardly tangible for empirical studies. The third level - and also the main object of study for semiotics - is intersubjective meaning. As the name suggests, intersubjective meaning is based on subjective meanings - or rather, intersubjective meanings are subjective meanings that are more or less similar or shared between different subjects.

\section{Competence}

I will now turn to the question concerning the subject. Elaborating on the definition above, I would like to pertain to the idea that the subject is not merely a living being, but can be perceived as an entity that acts, or takes action, and thus has the ability to, for example, carry out deeds and experience meanings. This internal ability can be referred to with the theoretical concept of competence (Greimas \& Courtés, 1982 pp. 44-46). A competence is a feature or property of a subject that differs from the 'regular' properties such as color, size, form and density because competences are not empirically accessible. The competence of a subject can only be deduced based on how it can be observed in action (Greimas, 1979) ${ }^{4}$. Actually this deduction goes so that we call some process action and some part of it subject if we can imagine and believe that the subject has competencies to do the deeds and experience the meanings required for that kind of action. Intentionality is a central part of action competences. The ability to experience certain meanings is called semiotic competence.

Competences vary among different subjects. Also, the competences of a subject are not stable but may change through time. The changes that take place regarding a subject's competences are what we mainly and traditionally mean by the term learning; more specifically, certain competences changes are perceived as learning. There are different ways in which competences may change. They can possibly change randomly; they might perhaps change through time during a subject's 
biological (and psychological) maturing processes; or thirdly, they can change as a result of a subject's own action. These three ways may be all operating together and there can be still other ways. However, usually only the third possibility is what is most commonly referred to as learning.

Learning is a significant concept, because it offers a possibility to examine the deliberate causing of competence changes and creation of new competences. The action where somebody is trying to change - usually to increase, improve or create - another individual's competences can be called teaching. Teaching takes place when a teacher somehow causes meaning effects that cause the learner to act in such a way that its competences would change in a desired way. It must be acknowledged that this complex endeavor is highly a fragile and risky process.

I have now considered general action theoretical questions at a bio-semiotical level. The difference between human and other living beings has not been established - even the example provided above case was deliberately chosen from a zoo-semiotic sphere. Traditionally, education has been perceived as a specifically human affair. In other words, as Kant (1992 p. 6) puts it, as a transfer from natural existence to human and cultural existence. However, in order to examine this idea of humanization a theoretical structure is required that would merge the imagined borderline that separates humans from other living beings. Before moving on to the area of human education, I will conclude this action theoretical view with the next figure:
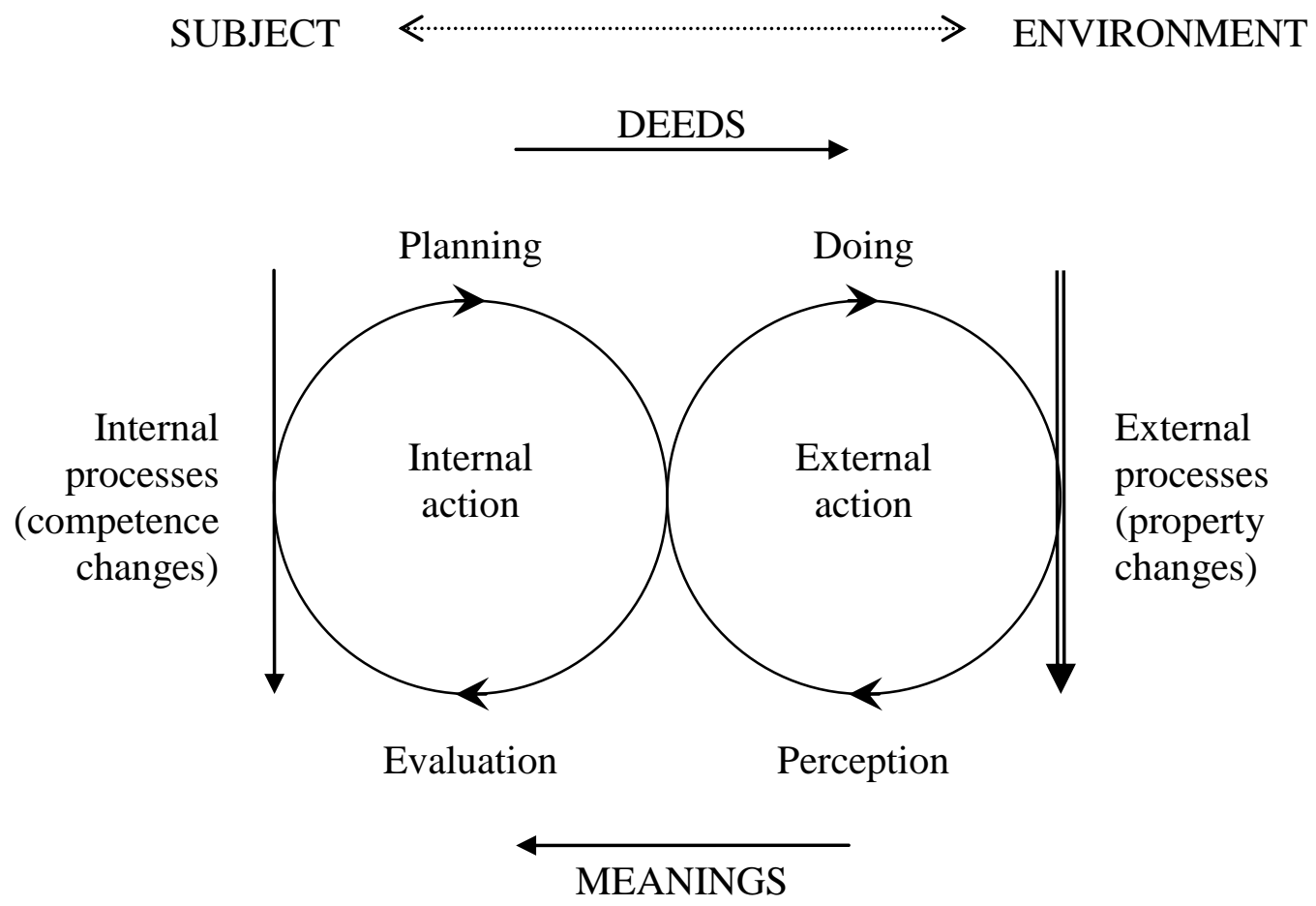
Figure 1. Circles of action

In Figure 1, the horizontal two-way arrow between the subject and the environment means that there is no clear cut borderline between them - nor between the internal and the external. However, there is something that is clearly external and empirically accessible; namely, the changing physical properties of subject's environment, as well as the subject's own body. Furthermore, there is something which is very well hidden from senses and empirical studies: the competences of the subject and the contents of its thinking activity. This hidden area is what is usually regarded as the core of subjectivity. Action, as a whole, consists of interaction between these internal and external areas. The effects of the internal side are deeds, and those of the external are meanings; the previous are causal and the latter are not.

The downward arrows describe the internal and external processes in time. Deeds affect external processes causal ways that can be identified. However, it goes without saying that explicating how competences are affected is not so easy - if at all possible - through scientific, empirical methods. The circular action as interaction between the environment and the subject is also divided into external and internal circles. External action refers to causal and empirical senso-motoric events. Internal action, on the other hand, refers to thinking. Although the action of thinking has been studied to some extent, for example, in brain research, it must be noted that the study of the contents of thinking is hardly feasible. In the portrayed model, the action of thinking has been simplified to the mere planning of deeds and evaluation of perceptions. What is important for human action is that this internal action can be more or less independent of the external, so that the subject can plan deeds it will never do and evaluate perceptions it has never obtained.

\section{Learning}

I will now proceed to consider the problems of human education, and will start by separating different but hierarchically nested cases or levels of learning. I will refer to the first level as the psychological level, at which any kind of competence change is somehow a result of a subject's own action. This is what is usually studied in psychological laboratory research. The second level is instructional learning. Here, the learning is typically - although not necessarily - influenced by teaching or instruction. At the instructional level, subjects learns something which is somehow valuable or useful. They learn how to reach a goal through action. (That goal can be either set by the subject, an instructor, or both combined.) In such a form of learning, a qualitative transfer takes place from a state of 'not-knowing-how' to the state of 'knowing-how'. The evaluation of this kind 
of 'knowing-how' competence is difficult because the learner can a) randomly succeed in reaching the goal; b) strive towards the wrong goal and nevertheless reach the correct goal accidently, or c) in a narrowed down manner, reach the right goal in a certain kind of environment only, and not in any other ${ }^{5}$.

The third and highest level of learning is the learning of competences that is specific to human life. This idea is based on the presupposition that there is a specifically human kind of action which requires certain kinds of competences. Traditionally, human action (human existence) has been perceived as containing properties such as culture, language, rationality, consciousness (especially self-consciousness), freedom, sociality etc. In the Continental tradition of educational thought, this idea has been central and is most commonly referred to as Bildung ${ }^{6}$. The concept of Bildung refers both to the process of learning and growth and also to the human and cultural values as contents of that process.

Bildung can be perceived as a process in which human beings learn to carry out significant deeds, participate in cooperation, interact in society, and most importantly, acquire the semiotic competence required for intersubjective meaning making within a culture. To a certain extent, the contents of Bildung must be left open, or undefined, because of the unavoidable, necessary, and desired historical changes within human societies and cultures. Furthermore, due to the ideas of freedom, rationality and ethics as cores of human action, Bildung cannot be determined beforehand. Human subjects must choose and decide for themselves what kind of future they desire. Therefore, Bildung is not strictly limited to individual learning and competences but it is also connected to changes in intersubjective meanings and thus also in human cultures.

\section{The paradoxical meaning of education: an analysis through the semiotic square}

This open-endedness and freedom within Bildung poses, still, a crucial problem for human education and teaching. Teaching (also referred to as instruction, upbringing, or advising) as direction and guidance always implies an interference with the learner's free action and thus a certain kind of coercion. This contradiction lead Kant (1992 p. 27) to his famous question: How can I cultivate freedom by coercion? Later this problem has been called the pedagogical paradox and it is perhaps still the main problem of educational theory. This paradox can, to some extent, be resolved by recognizing that learning takes place only through the subject's own action, and that the educator can influence the learner's action mainly through meaning effects. Thus, it can be derived 
that educational coercion is not physical determination, which Kant considers as the opposite of human freedom.

Furthermore, we can see some freedom in education if we compare it to the concept of communication. Here, I define communication as action in which a subject is trying to cause certain meaning effects in another subject. Ideally, communication is successful, reciprocal and transparent.. Such a situation requires exact, shared intersubjective meanings, in other words, a common language. In an educational situation, where the educator is trying to change the semiotic competence of the learner by teaching a new sign system, the sign system and its meanings cannot by definition be shared and common. Therefore, communication in education is always opaque, one-sided and leads to unexpected results.

However, the relationship between freedom and coercion it is not the only paradoxical contradiction or tension in education. Another tension can be found between the individual and society (Mielityinen, 2009). The individual is not only adapting to prevailing society but is also influencing the society and creating his/her own identity. These two paradoxes are, of course, interconnected although not the same; they both can be perceived as special variations or appearances of Rousseau's conflict between nature and society. In recent theories of pedagogical action, attempts have been made to resolve these contradictions with four interconnected principles or concepts: growth-ability (Bildsamkeit), the demand for autonomous action, contextuality, and a better future (see Mollenhauer, 1985, Benner, 1996, Kivelä, 1994).

These core contradictions of education also have a close relationship to the semiotic theory of A. J. Greimas. Greimas separates two kinds of meaningful sign structures or discourses: individual and collective (Greimas \& Courtés, 1982 p. 361). Both of these sign structures have basic fundamental value structures which differentiate them from each other. The individual (or idiolectal) discourse has basic values of Life and Death and the collective (or sociolectal) has values of Culture and Nature $^{7}$. The individual discourses seem to refer to the bio-semiotical level considered in the beginning of this article while the collective discourses refer to the human level. These value structures can be thought to be connected in either way: The 'Culture vs. Nature' division can be derived from Life, and on the other hand, the 'Life vs. Death' tension is a question regarding Nature. Thus it could be suggested that human education is a sociolectal structure where the individual side is somehow embedded mainly in the Nature pole. This value structure can be then analysed more profoundly by the semiotic square of Greimas. 
According to the structural tradition, Greimas proposes that meanings are based on difference and thus on binary oppositions. However, he further developed this basic binary structure into a square where there are different kinds of relations (1982). In addition, through this structure he was able to change the essentially static structural tradition to much more dynamic. In this square (see Figure 2) the horizontal lines represent opposite or contrary relations, the diagonal lines represent contradictory relations and the vertical lines demonstrate complementary (or enabling) relations. What is important is that while the binary opposition, or here, the relation between the counterpoints such as Culture vs. Nature, black vs. white, good vs. bad, man vs. woman etc. are quite stable and passive structures while the other relations are dynamic and active. There is a route, a dialectical process through which something can change from one contrary term to its counterpoint. For example, something 'good' is first negated via the contradictory relation 'notgood,' which can then become 'good' (see the instructive example in Floch, 2001 pp. 20-23).

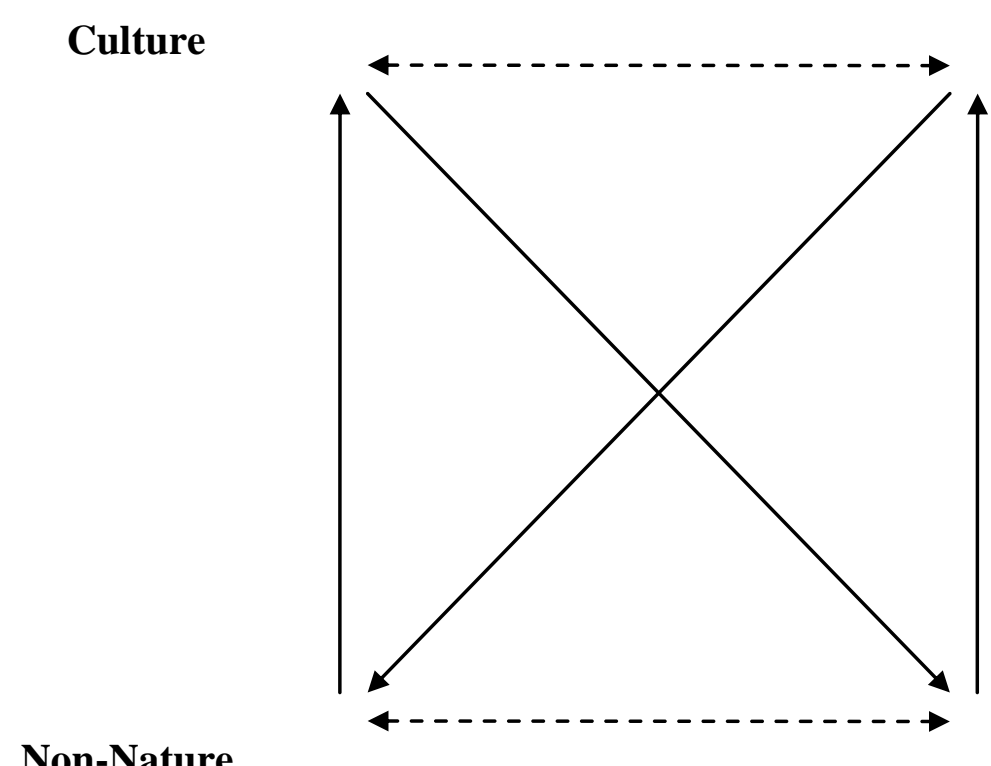

Non-Culture

Figure 2: Semiotic square of sociolectal basic values

In traditional examples of the semiotic analyses of folk tales, there is a strong axiological evaluation of the sociolectal basic values in which Culture is good and valuable and Nature is bad and dangerous. For example the basic structure in many well-known dragon and prince fables is such that the assault of the dragon (when it steals the princess) is the negation of Culture, which enables the empowerment of Nature. The prince then attacks the dragons cave and kills it (the negation of Nature), which enables him to save the princess (restoring the strength of Culture). 
In education this kind of one-sided axiological evaluation is problematic. Stables (2009) suggests that in the history of educational thought the Romantic movement over-valued the Nature, respectively we can presume that some Educational thinkers of Enlightenment have over-valued the Culture. The paradoxical tensions of education suggest that we cannot choose one side or not even the harmony of the poles, but the essence of modern education is precisely based on the dynamic contradictions between Culture and Nature ${ }^{8}$. Therefore, the positioning of the previously mentioned main principles of the theory of pedagogical action in the corners of the semiotic square would seem appropriate (see Figure 3). The individual growth-ability (the presupposed competences) represents Nature; the demand for autonomous action (teaching) represents Non-Nature; contextuality represents the prevailing Culture; and a better future represents Non-Culture. According to this analysis there is in education a double-dialectical process where the negation of Nature (cf. discipline) makes cultural existence possible and the negation of Culture (cf. critical education) makes natural existence possible.

\section{Culture}

Contextuality

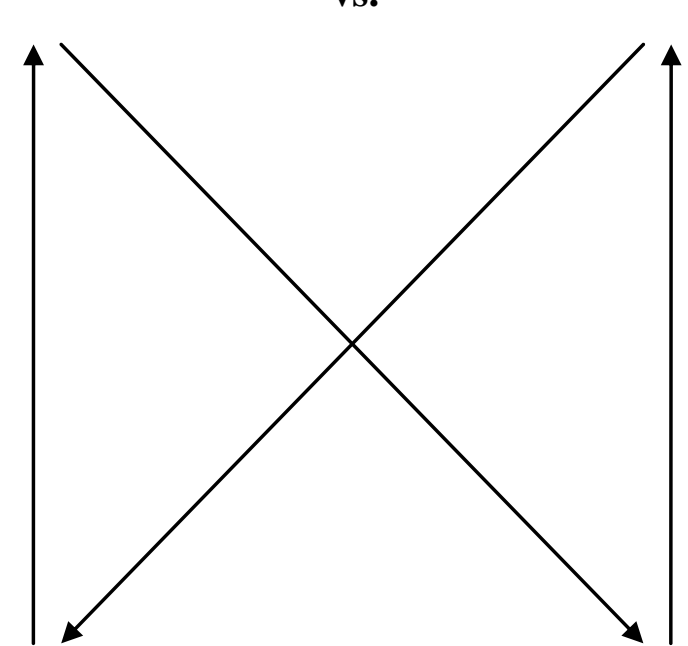

Non-Nature

Demand for autonomous action
Nature

Growth-ability

Figure 3: Semiotic square of education

Non-Culture

Better future

\section{Notes}


Until recent years, this important concept has been quite unknown in Anglo-American educational discussions; a few thorough(?) studies and introductions have been published in English (Westbury et al., 2000, Løvlie et al., 2003) and international research and dialogue on the subject has become more vibrant.

2 Language learning (Ajayi, 2009, Bezemer \& Kress, 2008, Suhor, 1991) and arts (Ranker, 2008, Dunbar-Hall, 1991) have often been of central concern in such studies, as well as mathematics (Bjuland et al., 2008, Botzer \& Yerushalmy, 2008) and science education (Groisman \& et al., 1991, Harris \& Williams, 2007, Pata et al., 2007).

3 A sign is a relatively stable part of a meaningful sign structure. In the previous example, the tree can be defined as a sign. It is more or less the same object whether it is rooted firmly to the ground or whether it is falling, but depending on these different circumstances its meaning can be very different. For human beings, especially, the creation of different meaning effects by combining the same signs in different ways is very important. In Greimassian tradition these meaningful ensembles of signs are called discourses.

4 The concept of competence can be compared to that of disposition. The latter belongs to the physical sphere, alike the concept of causality. In certain causal conditions the disposition (for example, fragility) of an object (for example, window) necessarily expresses a certain feature (brokenness) (see Armstrong et al., 2002), but the competence of a subject appears as an action only if the subject decides to act.

5 This evaluation is just as challenging (if not more so) for the learner him/herself as for the teacher. This explains the retrospective and narrative character of learning which Stables (2005) describes.

6 See footnote 2 .

7 Greimas developed a multi layered theory of discourse partly inspired by Chomsky's notions of deep and surface levels of language. Greimas called his theory as Generative trajectory. In the deepest level there is the basic or fundamental value structure. After then comes a narrative level where is described the basic abstract action structures and actant roles, In still more surface levels there are added time, place and actor structures and their detailed features etc. (Greimas \& Courtés, 1982 pp. 132-134)

8 It seems that this idea was already formed by Rousseau (Kontio, 2009).

\section{References}

Ajayi L. (2009) English as a Second Language Learners' Exploration of Multimodal Texts in a Junior High School. Journal of Adolescent \& Adult Literacy 52: 7, pp. 585-595.

Armstrong, D. M., Martin, C. B., Place, U. T. \& Crane, T. (2002) Dispositions: a debate. (London, Routledge).

Benner, D. (1996) Allgemeine Pädagogik : eine systematisch-problemgeschichtliche Einführung in die Grundstruktur pädagogischen Denkens und Handelns. 3. Aufl (Weinheim, Juventa).

Bezemer J. \& Kress G. (2008) Writing in Multimodal Texts: A Social Semiotic Account of Designs for Learning. Written Communication 25: 2, pp. 166-195.

Bjuland R., Cestari M. L. \& Borgersen H. E. (2008) The Interplay Between Gesture and Discourse as Mediating Devices in Collaborative Mathematical Reasoning: A Multimodal Approach. Mathematical Thinking \& Learning 10: 3, pp. 271-292.

Botzer G. \& Yerushalmy M. (2008) Embodied Semiotic Activities and Their Role in the Construction of Mathematical Meaning of Motion Graphs. International Journal of Computers for Mathematical Learning 13: 2, pp. 111-134. 
Davis, L., H. (1979) Theory of Action. (Englewood Cliffs (N.J.), Prentice-Hall, Inc.).

Dunbar-Hall P. (1991) Music and Language: Commonalities in Semiotics, Syllabus, and Classroom Teaching. Music and Language: Commonalities in Semiotics, Syllabus, and Classroom Teaching

Floch, J. (2001) Semiotics, marketing and communication: beneath the signs, the strategies. (Basingstoke, Palgrave,).

Greimas A. J. (1979) Pour une sémiotique didactique. Bulletin du Groupe recherches sémiolinguistiques : 7, pp. 3-8.

Greimas, A. J. \& Courtés, J. (1982) Semiotics and Language: An Analytical Dictionary. (Bloomington, Indiana University Press).

Groisman A. \& et al. (1991) The Potential of Semiotics to Inform Understanding of Events in Science Education. International Journal of Science Education 3: 13, pp. 217-226.

Harris D. \& Williams J. (2007) Questioning 'Open questioning' in early years science discourse from a social semiotic perspective. International Journal of Educational Research 46: 1, pp. 68-82.

Kant, I. (1992) Kant on Education. (Bristol, Thoemmes Press).

Kivelä, A. (1994) Pedagoginen toiminta - paradoksiko? Lähtökohtia sivistysteoreettisesti orientoituneelle pedagogisen toiminnan rekonstruktiolle. [unpublished thesis] (Oulu, [A. Kivelä]).

Kontio K (2009) Rousseau's Pedagogical Legacy (Unpublished conference paper in Sixteenth Biennial Colloquium of the Rousseau Association in Los Angeles, California, USA, 25-28 June, 2009).

Løvlie, L., Nordenbo, S. E. \& Mortenson, K. P. (2003) Educating humanity: Bildung in posmodernity. (London, Blackwell).

Mielityinen, M. (2009) Das Ästhetische in Schleiermachers Bildungstheorie. Theorie eines individuellen Weltbezuges unter Einbeziehung der Theorie des Ästhetischen bei Schiller. (Würzburg, Ergon-Verlag).

Mollenhauer, K. (1985) Vergessene Zusammenhänge: Über Kultur und Erziehung. (München, Juventa Verlag).

Moya, C. (1990) The Philosophy of Action: An Introduction. (Cambridge, Polity Press).

Pata K., Pedaste M. \& Sarapuu T. (2007) The Formation of Learners' Semiosphere by Authentic Inquiry with an Integrated Learning Object "Young Scientist". Computers \& Education 49: 4, pp. 1357-1377.

Pikkarainen, E. (2004) Merkityksen ongelma kasvatustieteessä: Lähtökohtia pedagogisen toiminnan perusrakenteen semioottiseen analyysiin. (Oulu, Oulun yliopisto).

Ranker J. (2008) Composing across Multiple Media: A Case Study of Digital Video Production in a Fifth Grade Classroom. Written Communication 25: 2, pp. 196-234.

Stables, A. (2005) Living and learning as semiotic engagement: a new theory of education. (Lewiston, Edwin Mellen Press).

Stables A. (2009) The Unnatural Nature of Nature and Nurture: Questioning the Romantic Heritage. Studies in Philosophy \& Education 28: 1, pp. 3-14.

Stables A. \& Gough S. (2006) Toward a semiotic theory of choice and of learning. Educational Theory 56: 3, pp. 271-285.

Stockinger, P. (1989) Prolegomena to a Theory of Action. In: P. Perron \& Collins F. (eds.) Paris School of Semiotics I: Theory. (Amsterdam, John Benjamins). pp. 33-60.

Suhor C. (1991) Semiotics and the English Language Arts. ERIC Digest. CS- ERIC Clearinghouseon Reading and Communication Skills, Bloomington. 2009: 7/2.

Westbury I., Hopmann S. \& Riquarts K. (eds) (2000) Teaching as a reflective practice: the German didaktik tradition. (Mahwah (N. J.), Lawrence Erlbaum Associates).

von Uexküll J. (1982) The Theory of Meaning. Semiotica 42: 1, pp. 25-82. 